\title{
Quantitative molecular grading of bladder tumours: A tool for objective assessment of the biological potential of urothelial neoplasias
}

\author{
DANIEL BOLLMANN ${ }^{1}$, MAGDOLNA BOLLMANN ${ }^{1}$, \\ AGNES BANKFALVI $^{2}$, HILDEGARD HELLER ${ }^{1}$, REINHARD BOLLMANN ${ }^{1}$, \\ GABOR PAJOR $^{3}$ and RALF HILDENBRAND ${ }^{1}$
}

${ }^{1}$ Institute of Pathology, Bonn-Duisdorf; ${ }^{2}$ Institute of Pathology and Neuropathology, University Clinic, Essen, Germany; ${ }^{3}$ Department of Pathology, Medical Faculty, University of Pécs, Hungary

Received July 1, 2008; Accepted September 2, 2008

DOI: 10.3892/or_00000187

\begin{abstract}
The present study aimed to assess whether patients with bladder urothelial tumours can be more objectively stratified into low- and high-risk groups for recurrence and progression using a 2-tired molecular grading scheme, than by subjective histopathological grading alone. Biopsy material from 45 consecutive patients with urothelial bladder neoplasias (2 papillary urothelial neoplasm of low malignant potentials, $18 \mathrm{pTa}, 1$ pTis, 19 pT1 and 5 pT2) was analysed for immunohistochemical Ki-67 and p53 expression. Labelling indices were assessed by automated cellular image analysis. UroVysion FISH test results were evaluated by automated signal counting, and DNA ploidy of single nuclei preparations were measured by image cytometry. Sixty-nine percent of cases showed $>10 \%$ Ki-67 LI, $64 \%$ had $>10 \%$ p53 LI, $53 \%$ revealed DNA aneuploidy and 56\% expressed a high-risk FISH pattern. Based on a combination of single molecular markers, $75 \%$ of neoplasias were classified as high molecular grade. Tumour stage and histopathological grade were significantly associated with FISH pattern, DNA ploidy and MIB1 LI. Stage was also related with molecular grade. Clinical outcome showed a significant correlation with MIB1 LI and molecular grade. P53 had neither diagnostic nor prognostic relevance, nor was there any correlation between histological and molecular grade. Our preliminary data strongly suggest that the combination of quantitative biomarkers provides superior and objective prognostic tools in bladder urothelial neoplasias compared to classic clinicopathological features and indices.
\end{abstract}

Correspondence to: Dr Agnes Bankfalvi, Institute of Pathology and Neuropathology, University Clinic, Essen Hufelandstrasse 55, D-45122 Essen, Germany

E-mail: agnes.bankfalvi@uk-essen.de

Key words: bladder cancer, biomarkers, molecular grading, image morphometry, prognosis

\section{Introduction}

Most malignant neoplasms of the urinary bladder are urothelial carcinomas (UC), which frequently occur multifocally and have various clinical manifestations with different prognostic and therapeutic implications. Clinical diversity is associated with pathological and molecular dichotomy. Low-grade, superficial bladder cancers have a propensity to recur but are at minimal risk for progression and tumour-related death. In contrast, high-grade, muscle-invasive cancers often metastasise, resulting in poor clinical outcome (1). Clinical and pathological prognostic factors have been studied extensively $(2,3)$. Despite well-recognized limitations of pathological assessment (4), stage and grade remain the standard estimates for outcome prediction. Recently, the European Organization for Research and Treatment of Cancer (EORTC) developed risk tables based on the combination of six routinely assessed factors: prior recurrence rate, number of tumours, tumour size, pT stage, grade and concomitant carcinoma in situ to predict the probability of recurrence and progression in individual patients (5).

However, the prognosis of patients, particularly of those labelled with 'superficial' bladder cancer is greatly variable. Therefore, there is a need to develop objective markers that can augment morphological risk assessment and assist therapy decisions.

Several biomarkers have been investigated for their role in the development and progression mechanisms of bladder carcinoma. Oncogenes, tumour suppressor genes and associated cell-cycle proteins, growth factors, cell adhesion molecules and chromosomal alterations have been identified in UC $(6,7)$. Some of them hold considerable promise in the assessment of tumour aggressiveness [e.g. p53 (8), Ki67/MIB1 $(9,10)$ and DNA ploidy $(11,12)]$. However, only a few studies have analysed the validity of multiple molecular markers, which revealed that combinations improve the prediction of disease course and patient survival (2,13-15).

To examine the nature and discriminative power of genetic instability, our investigators explored the use of the UroVysion FISH test, which detects the aneusomy of chromosomes 3, 7 
and 17, and loss of the 9p21 locus, to define distinct chromosomal patterns in urine cytology samples of patients with superficial bladder cancer (16). Our pilot results suggested that the measurement of generalized chromosome polysomy may provide a genetic marker for assessing the risk of recurrence and progression in patients with superficial urothelial neoplasias.

The present study aimed to expand on the previous investigation of measuring chromosome polysomy in urine cytology by FISH to histological samples of bladder tumours and evaluate whether a combined molecular grade, composed of FISH pattern, morphometric estimates of immunohistochemical Ki-67 and p53 expression and DNA ploidy can provide tools for a more objective stratification of bladder cancer patients into low- and high-risk groups than subjective histopathological grading.

\section{Materials and methods}

Patients and tissues. Routinely formalin-fixed and paraffinembedded urinary bladder biopsy specimens from 45 consecutive patients (38 men and 7 women; mean age 68.4 years, range 45-86) with new or recurrent urothelial neoplasms diagnosed between January 1, 2004 and June 30, 2007 were investigated. Twenty-two patients were under surveillance for recurrence of superficial bladder cancer after complete transurethral resection (TUR). Cystectomy was performed in nine patients who had multiple recurrences at repeated cystoscopies. Nephrectomy was performed in two patients who developed ureteral carcinomas in addition to their bladder tumours. Tissue biopsies were obtained in different outpatient urological practices and hospitals from the federal state of North Rhine-Westphalia, West Germany and sent to the Institute of Pathology in Bonn for routine histological diagnosis.

Follow-up. After surgery, follow-up was performed prospectively with urine cytology and cystoscopy including directed biopsy if indicated. Twenty-two patients were eligible for disease outcome assessment, with a mean follow-up of 34.41 months (range 3-152). Cases with recurrence within 3 months of the primary diagnosis were considered to have residual primary tumours rather than true recurrences and were classified together with the diagnostic cases. To assess clinical outcome, the categories used were: i) uneventful, no signs of disease recurrence or progression during follow-up; ii) recurrence only, reappearance of neoplasia after therapy in the same stage and grade as the primary tumour; and iii) progression, disease reappearance in advanced stage and/or grade.

Histological analysis. H\&E-stained slides were reviewed and classified independently by two pathologists (D.B. and M.B.). Staging and grading were performed according to the 2002 TNM classification (17) and the 1999 WHO system (18), respectively. In case of disagreement, slides were re-examined and re-classified until a consensus was achieved. Histological diagnoses of primary bladder tumours included papillary urothelial carcinoma of grades $1(n=3), 2(n=10)$ and $3(n=17)$, while 12 cases not were graded unequivocally by histology (2 with grade 1-2 and 10 with grade $2-3$ ). Regarding stage distribution, pTis was found in 1, pTa in 18, pT1 in 19 and pT2 in 5 cases. Papillary urothelial neoplasm of low malignant potential (PUNLMP) was diagnosed in two patients. The characteristic histology of papillary UCs on $\mathrm{H} \& \mathrm{E}$ slides is shown in Fig. 1A-C.

p53 and MIB1 immunohistochemistry and scoring. The cases were stained for p53 (monoclonal mouse anti-human antibody clone DO 7, Ventana, Germany; ready-to-use) and Ki-67 (monoclonal mouse anti-human antibody, clone K-2, Ventana, Germany; ready-to-use) on $4 \mu \mathrm{m}$ serial deparaffinised and rehydrated paraffin sections following heat-induced epitope retrieval in $\mathrm{CC} 1$ buffer in the fully automated Ventana BenchMark XT System (Ventana Medical Systems Inc., Tuzson, AZ, USA) based on the avidin-biotin peroxidase method according to standard protocols. Development was performed using the iView polymer DAB detection kit. Established positive control sections were included in each run together with tumour tissue sections mounted on the same slides.

Staining results were quantitatively analysed using bright field microscopy imaging coupled with advanced colour detection software [Automated Cellular Imaging System (ACIS), ChromaVision Medical Systems Inc., San Juan Capistrano, CA]. Signal classification was based on predetermined colour morphology and reported as a percentage of stained tumour cells, staining intensity and histoscore (percentage of tumour cells plus staining intensity). A minimum of four distinct areas from each specimen were analysed in triplicate. Data were expressed as the mean \pm SD for the analyses. Thresholds for high labelling indices were set for $\mathrm{Ki}-67$ at $\geq 10 \%$ positive tumour nuclei and for p53 at 10 and $20 \%$, according to data from the literature $(10,14)$. Characteristic Ki-67/MIB1 and p53 immunohistochemical reactions and their morphometric evaluation results by Chroma Vision are shown in Fig. 1D-I.

Isolation of nuclei from paraffin-embedded tumour tissues for FISH and DNA image cytometry. Sections $(50 \mu \mathrm{m})$ were cut from the paraffin tissue blocks for nuclear extraction, deparaffinized in xylene $\left(60^{\circ} \mathrm{C}\right.$ overnight $)$ and rehydrated in a series of decreasing ethanol concentrations to water. Samples were digested in pre-warmed $0.5 \%$ pepsin solution $(\mathrm{pH} 1.5)$ for $60 \mathrm{~min}$ at $37^{\circ} \mathrm{C}$, washed in PBS two times by vortexing vigorously ( $3500 \mathrm{U} / \mathrm{min}$ for $10 \mathrm{~min}$ ) and resuspended in $0.5 \mathrm{ml}$ PBS. Two cytospins were prepared from each sample (Hettich cytospin; Andreas Hettich GmbH \& Co. KG, Tuttlingen, Germany), one for FISH and one for DNA image cytometry, and air-dried for storage.

UroVysion FISH on paraffin-extracted nuclei from urothelial neoplasias. The UroVysion FISH test was applied to cytospin preparations from the paraffin-extracted nuclei of urothelial neoplasias. Laboratory procedure was performed according to the manufacturer's instructions. Briefly, specimens were fixed in methanol/acetic acid for $10 \mathrm{~min}$ at $-20^{\circ} \mathrm{C}$ and digested by using $0.2 \mathrm{mg} / \mathrm{ml}$ pepsin in $0.02 \mathrm{~N} \mathrm{HCl}$ for $10 \mathrm{~min}$ at $37^{\circ} \mathrm{C}$ in a humidified chamber. Subsequently, slides were washed twice in $1 \mathrm{X}$ phosphate-buffered saline (PBS) for $5 \mathrm{~min}$ each at room temperature, fixed in $4 \%$ neutral-buffered formalin/PBS for 
।
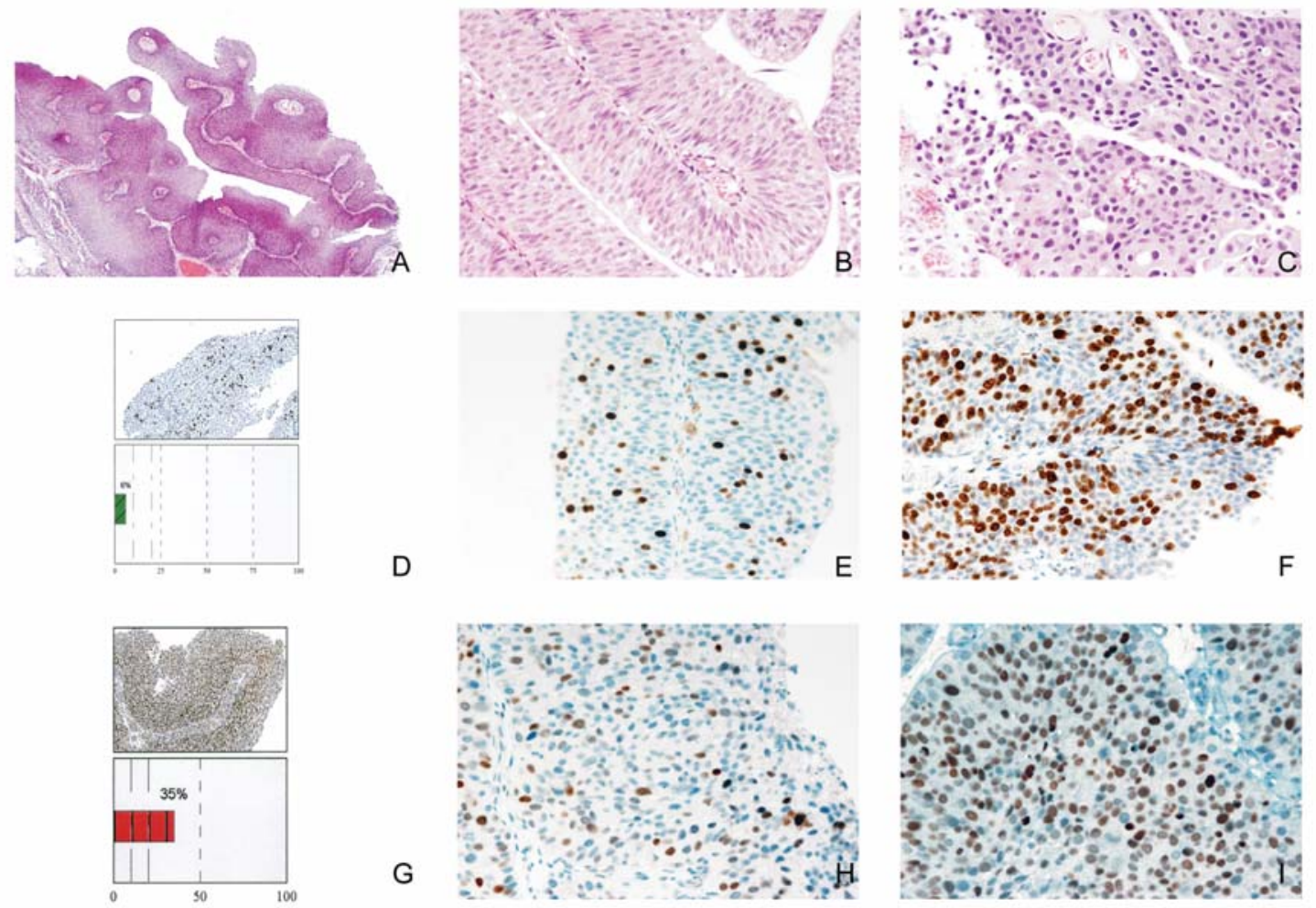

Figure 1. (A) Characteristic histology of a papillary urothelial neoplasia (magnification, x25). (B) Histology of a grade 1 papillary urothelial carcinoma (magnification, x400). (C) Histology of a grade 3 papillary urothelial carcinoma (magnification, x400). (D) Low Ki-67 LI as demonstrated by a characteristic ChromaVision panel. (E) Concurrent immunohistochemical appearance of low Ki-67 LI in a histological section of a papillary UC (magnification, x250). (F) Characteristic immunohistochemical appearance of high Ki-67 LI in a histological section of a papillary UC (magnification, x250). (G) High p53 LI as demonstrated by a characteristic ChromaVision panel. $(\mathrm{H})$ Characteristic immunohistochemical appearance of low p53 LI in a histological section of a papillary UC (magnification, x250). (I) Concurrent immunohistochemical appearance of high p53 LI in a histological section of a papillary UC (magnification, x250).

5 min, washed in $1 \mathrm{X}$ PBS for 5 min and dehydrated in an increasing ethanol series.

Then, $10 \mu 1$ of the hybridisation mix [ $8 \mu 1$ hybridisation buffer LSI-WCP (Vysis), $1 \mu 1$ distilled water and $1 \mu 1$ Urovysion probe mix, consisting of directly labelled fluorescent probes to the peri-centromeric regions of chromo-somes 3 (CEP-3-red), 7 (CEP-7-green) and 17 (CEP 17-aqua) and to the locus 9p21 (LSI 9p21-gold)], was placed on the target, coverslipped and sealed with rubber cement.

Following co-denaturation at $73^{\circ} \mathrm{C}$ for $10 \mathrm{~min}$, slides were incubated at $37^{\circ} \mathrm{C}$ overnight in a humidified chamber. Posthybridisation washings were performed in $2 \mathrm{X} \mathrm{SSC}$ at $73^{\circ} \mathrm{C}$ and in $2 \mathrm{X} \mathrm{SSC}$ at room temperature for $2 \mathrm{~min}$ each. 4.6Diamidine-2-phenylindole dihydrochloride (DAPI) was used for counterstaining.

Evaluation of FISH signals. Each case was evaluated by an independent scientist (H.H.), experienced with FISH analysis, who was blinded to clinical or histological findings. Slides were scored for hybridisation signals using a Zeiss Axioplan fluorescence microscope (Zeiss, Jena, Germany) with an appropriate filter set at a magnification of $\mathrm{x} 400$. Spot counting was performed by automatic interphase FISH analysis using the Metafer-Metacyte slide scanning system (Metasystems $\mathrm{GmbH}$, Altlussheim, Germany). A minimum of 30 abnormal nuclei per slide was evaluated in each case and 30 normalappearing urothelial or lymphoid cell nuclei in the same cytospin were analysed for internal control. FISH results were considered positive if: i) 10 or more nuclei exhibited deletion of 9p21 (monozygous or heterozygous), ii) 10 or more nuclei exhibited polysomy of one chromosome, or iii) a minimum of 5 nuclei exhibited polysomy of $>1$ chromosome per cell (Vysis-Abbott Diagnostics). Tetraploid chromosomal sets were not considered as a sign of malignancy.

The mean copy number of each chromosome (CI, chromosome index; the total number of hybridisation signals divided by the total number of nuclei analysed) and the frequency of polysomies (PI, polysomy index; the percentage of scored nuclei exhibiting $\geq 3$ chromosome copies) were calculated to estimate the degree of chromosome instability in each case.

None of the urothelial neoplasias with the disomic chromosomal pattern had negative FISH results. Therefore, FISH results were classified into 2 groups for prognostic analysis: i) low-risk, showing loss of 9p21 either as the only chromosomal aberration or accompanied by single cells $(<10 \%)$ with tri- or tetrasomy/ies of either or all the chromosomes 3,7 and 17, and ii) high-risk, revealing loss of 9 p21 and $>10 \%$ aneusomy/ies for either or all marker chromosomes. A characteristic panel of a Metafer-Metacyte gallery with images of selected atypical nuclei of UCs after UroVysion FISH is shown in Fig. 2A-C.

DNA image cytometry on paraffin-extracted nuclei from urothelial neoplasias. A second cytospin preparation of the same nuclear suspension prepared for FISH analysis was 

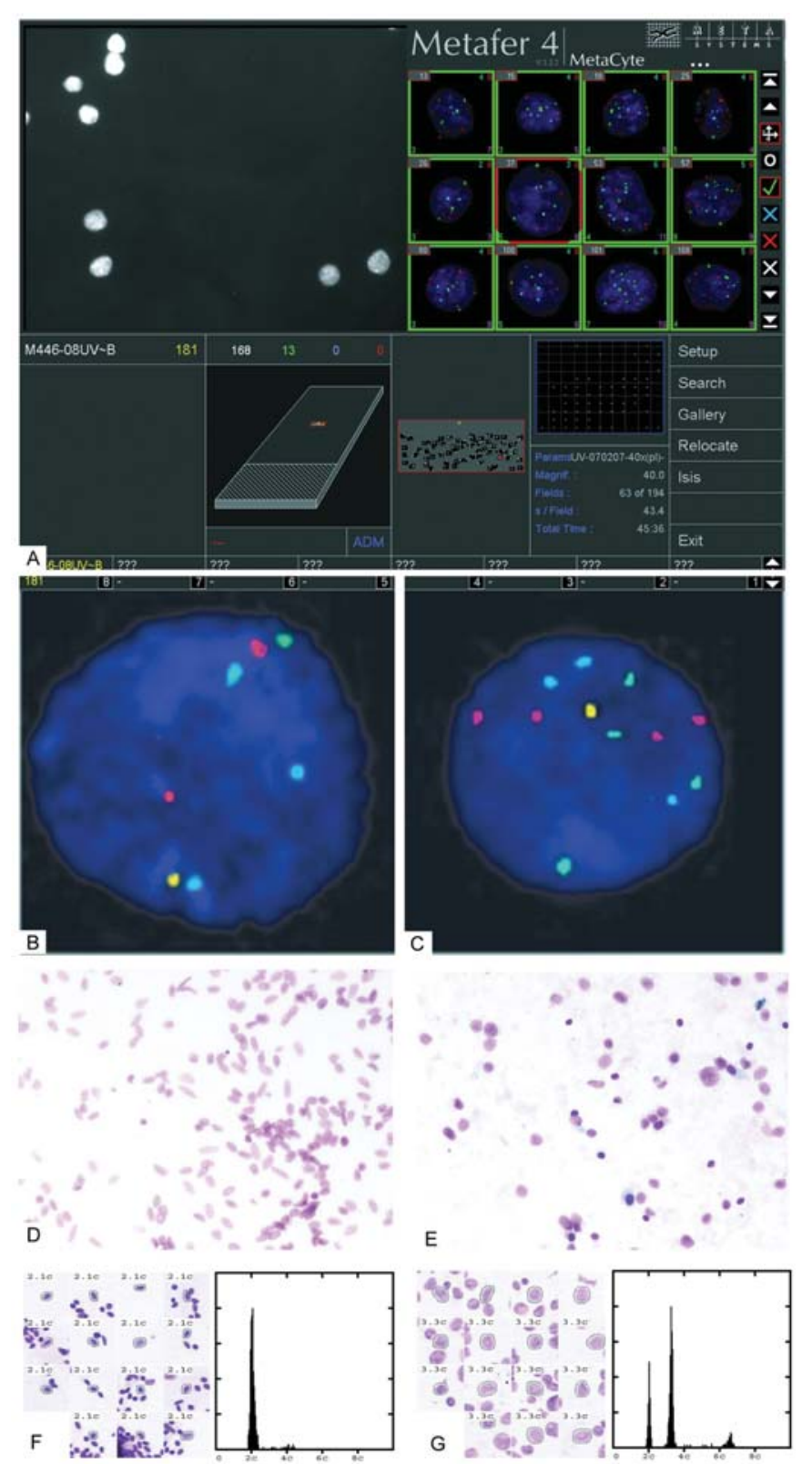

Figure 2. (A) Characteristic panel of a Metafer-Metacyte gallery with images of selected atypical nuclei after multicolour, multiprobe FISH (UroVysion). (B) UroVysion FISH result showing low-risk FISH pattern with heterozygous deletion of 9p21 (one gold signal) and disomy of chromosomes 3 (red), 7 (green) and 17 (aquamarine). (C) UroVysison FISH result showing high-risk FISH pattern with heterozygous deletion of $9 \mathrm{p} 21$ (one gold signal) and different polysomies of chromosomes 3 (four red signals, 7 (four green signals) and 17 (three aquamarine signals). Feulgenstained extracted nuclei from (D) diploid and (E) aneuploid lesions (magnification, x100, respectively). Concurrent set of measured nuclei and DNA ploidy diagram from (F) diploid and $(\mathrm{G})$ aneuploid lesions.

stained according to the Feulgen method. For the measurements, a PC-based image analyser (ACAS; Ahrens, Bargteheide, Germany) with special DNA software was used. To assess the diploid ( $2 \mathrm{c}$ ) range, the integrated optical density of the nuclei of 30 lymphocytes or normal urothelial cells in the cytospins was analysed. The CV value of these reference cells was not to exceed 5\%. Subsequently, at least 250 tumour cell nuclei were measured selectively in each sample. Only intact, non-overlapping nuclei were included in the analysis.
Table I. Patient and tumour characteristics $(n=45)$.

\begin{tabular}{|c|c|c|}
\hline & $\mathrm{n}$ & $\%$ \\
\hline \multicolumn{3}{|l|}{ Gender } \\
\hline Male & 38 & 84.4 \\
\hline Female & 7 & 15.6 \\
\hline \multicolumn{3}{|l|}{ Entity } \\
\hline PUNLMP & 2 & 4.4 \\
\hline pTis UC & 1 & 2.2 \\
\hline pTa UC & 18 & 40.0 \\
\hline pT1 UC & 19 & 42.2 \\
\hline pT2 UC & 5 & 11.1 \\
\hline \multicolumn{3}{|c|}{ Histological grade (WHO 1999) } \\
\hline 1 & 3 & 7.1 \\
\hline $1-2$ & 2 & 4.8 \\
\hline 2 & 10 & 23.8 \\
\hline $2-3$ & 10 & 23.8 \\
\hline 3 & 17 & 40.5 \\
\hline \multicolumn{3}{|l|}{ FISH pattern } \\
\hline Low-risk & 20 & 44.4 \\
\hline High-risk & 25 & 55.6 \\
\hline \multicolumn{3}{|l|}{ DNA ploidy } \\
\hline Diploid & 21 & 46.7 \\
\hline Non-diploid & 24 & 53.3 \\
\hline \multicolumn{3}{|l|}{ p53 expression } \\
\hline Negative $(<10 \%)$ & 16 & 35.6 \\
\hline Positive (>10\%) & 29 & 64.4 \\
\hline \multicolumn{3}{|c|}{ MIB1 labelling index } \\
\hline Low $(<10 \%)$ & 14 & 31.1 \\
\hline High $(>10 \%)$ & 31 & 68.9 \\
\hline \multicolumn{3}{|l|}{ Molecular grade } \\
\hline Low & 7 & 15.5 \\
\hline High & 38 & 74.5 \\
\hline
\end{tabular}

PUNLMP, papillary urothelial neoplasm of low malignant potential.

Data were interpreted using the analysis software of the system. DNA histograms were classified as: i) diploid (stem line DNA peak between 1.80 and $2.20 \mathrm{c}$ ), ii) polyploid (at least two stem lines between 1.8-2.2 and 3.6-4.4 c, or $\sim 8$ and $16 \mathrm{c}$ ) and iii) aneuploid (abnormal stem line beyond diploid or polyploid peaks, and/or $>10 \%$ of the nuclei showing DNA values $>5 \mathrm{c}$ and/or presence of single cells with DNA content $>9$ c). Characteristic examples of the Feulgen-stained nuclei from UCs with concurrent DNA-ploidy diagrams are shown in Fig. 2D-G.

Molecular grading. Based on the results of molecular tests, tumours were subdivided into: i) high molecular grade, showing aberrant expression of at least one of the four 
Table II. Relationship between tumour characteristics and molecular markers in 45 primary urothelial neoplasias.

\begin{tabular}{|c|c|c|c|c|c|c|c|c|c|c|}
\hline & \multicolumn{2}{|c|}{ FISH pattern ${ }^{\mathrm{a}}$} & \multicolumn{2}{|c|}{ DNA ploidy ${ }^{\mathrm{b}}$} & \multicolumn{2}{|c|}{ p53 expression ${ }^{\mathrm{c}}$} & \multicolumn{2}{|c|}{ MIB1 LI } & \multicolumn{2}{|c|}{ Molecular grade } \\
\hline & $\begin{array}{l}\text { Low- } \\
\text { risk }\end{array}$ & $\begin{array}{c}\text { High- } \\
\text { risk }\end{array}$ & Diploid & $\begin{array}{l}\text { Non- } \\
\text { diploid }\end{array}$ & $\begin{array}{l}\text { Negative } \\
<10 \%\end{array}$ & $\begin{array}{l}\text { Positive } \\
>10 \%\end{array}$ & $\begin{array}{c}\text { Negative } \\
<10 \%\end{array}$ & $\begin{array}{l}\text { Positive } \\
>10 \%\end{array}$ & Low & High \\
\hline \multicolumn{11}{|c|}{ Histology of bladder neoplasias and stage, if appropriate } \\
\hline PUNLMP $(n=2)$ & 2 & 0 & 2 & 0 & 2 & 0 & 2 & 0 & 2 & 0 \\
\hline pTis $(n=1)$ & 0 & 1 & 0 & 1 & 0 & 1 & 0 & 1 & 0 & 1 \\
\hline $\mathrm{pTa}(\mathrm{n}=18)$ & 14 & 4 & 16 & 2 & 8 & 10 & 9 & 9 & 3 & 15 \\
\hline pT1 $(n=19)$ & 4 & 15 & 3 & 16 & 4 & 15 & 2 & 17 & 1 & 18 \\
\hline pT2 $(n=5)$ & 0 & 5 & 0 & 5 & 2 & 3 & 1 & 4 & 1 & 4 \\
\hline Total $(n=45)$ & 20 & 25 & 21 & 24 & 16 & 29 & 14 & 31 & 7 & 38 \\
\hline \multicolumn{11}{|l|}{ Grade (WHO 1999) } \\
\hline $1(n=3)$ & 2 & 1 & 3 & 0 & 2 & 1 & 3 & 0 & 1 & 2 \\
\hline $1-2(n=2)$ & 2 & 0 & 2 & 0 & 1 & 1 & 0 & 2 & 0 & 2 \\
\hline $2(\mathrm{n}=10)$ & 7 & 3 & 8 & 2 & 5 & 5 & 6 & 4 & 2 & 8 \\
\hline $2-3(n=10)$ & 6 & 4 & 5 & 5 & 2 & 8 & 2 & 8 & 1 & 9 \\
\hline $3(n=17)$ & 1 & 16 & 1 & 16 & 4 & 13 & 1 & 16 & 1 & 16 \\
\hline Total $(n=42)$ & 18 & 24 & 19 & 23 & 14 & 28 & 12 & 30 & 5 & 37 \\
\hline
\end{tabular}

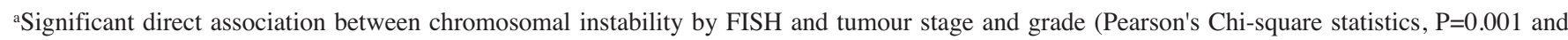
$\mathrm{P}=0.002$, respectively). ${ }^{\mathrm{b}}$ Significant direct association between DNA ploidy and tumour stage and grade (Pearson's Chi-square statistics, $\mathrm{P}=0.000$ and

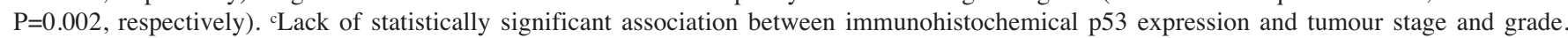
${ }^{\mathrm{d} S i g n i f i c a n t}$ direct association between MIB1 LI and tumour stage and grade (Pearson's Chi-square statistics, $\mathrm{P}=0.018$ and $\mathrm{P}=0.001$, respectively). ${ }^{\mathrm{e}}$ Significant direct association between molecular grade and tumour stage (Pearson's Chi-square statistics, $\mathrm{P}=0.013$ ), no significant association with histopathological grade.

biomarkers investigated (high-risk FISH, or non-diploid DNA content, or p53 LI $\geq 10 \%$ or MIB LI $\geq 10 \%$ ) and ii) low molecular grade, with molecular patterns below the threshold for high-grade (low-risk FISH and diploid DNA content and p53 LI $\leq 9$ and MIB LI $\leq 9$ ).

Statistical analysis. Descriptive statistics for continuous measures are given as the mean and/or median with minimum and maximum values. Pearson's Chi-square test was used to compare molecular patterns with clinical and pathological findings. Correlation between variables was computed using Spearman's rank analysis. Differences in the clinical outcome between patient groups with different histopathological and molecular patterns were evaluated by the Mann-Whitney U-test.

\section{Results}

Patient and tumour characteristics. The distribution of patient and tumour characteristics are shown in Table I. Primary urothelial neoplasias from 38 men and 7 women were included in the study, including 2 PUNLMPs, 19 non-invasive (intraepithelial) (1 pTis and 18 pTa), 19 superficially invasive (pT1) and 5 deeply invasive (pT2) carcinomas. The histomorphological tumour grade was defined unequivocally in 30 neoplasias (3 grade 1, 10 grade 2 and 17 grade 3 ) using the 3-tired WHO 1999 classification. Ambiguous grades (2 grade
1-2 and 10 grade 2-3) were given to 12 tumours based on histomorphology alone. In contrast, molecular patterns as single variables and combined molecular grades were classified according to a 2-tired system using the 2004 WHO histopathological classification (19).

Association of molecular patterns with pathological tumour characteristics. The differential expression of the four biomarkers and the combined molecular grade according to the morphological stage and grade of the tumours is shown in Table II. For the four biomarkers, the prevalence of alteration gradually increased from lower stage and grade tumours to more advanced ones. Statistically significant direct association was computed between the tumour stage and chromosomal instability [FISH pattern $(\mathrm{P}=0.001)$ ], DNA ploidy $(\mathrm{P}=0.000)$, MIB1 LI $(\mathrm{P}=0.018)$ and molecular grade $(\mathrm{P}=0.013)$. The histopathological tumour grade was significantly associated with the FISH pattern $(\mathrm{P}=0.002)$, DNA ploidy $(\mathrm{P}=0.002)$ and MIB1 LI ( $\mathrm{P}=0.001)$. No significant association was detected between p53 expression and either morphological variables, at neither the 10 nor $20 \%$ threshold. No significant association between the histomorphological and molecular tumour grades was found.

A statistically significant correlation between the morphological and molecular markers was found for histopathological grade and MIB1 LI (rs 0.475, P<0.001, Spearman's rank correlation), and for tumour stage with grade, FISH pattern, DNA 
Table III. Relationship of tumour characteristics and clinical outcome in 22 patients with urothelial neoplasias and follow-up.

\begin{tabular}{|c|c|c|c|c|c|c|}
\hline Variable & No. & $\begin{array}{c}\text { Uneventful } \\
\text { No. }\end{array}$ & $\begin{array}{c}\text { Recurrence only } \\
\text { No. }\end{array}$ & $\begin{array}{c}\text { Progression } \\
\text { No. }\end{array}$ & Chi-square & P-value \\
\hline Whole series & 22 & 5 & 11 & 6 & & \\
\hline \multicolumn{7}{|l|}{ Gender } \\
\hline Male & 20 & 5 & 10 & 5 & & \\
\hline Female & 2 & 0 & 1 & 1 & 0.630 & NS \\
\hline \multicolumn{7}{|l|}{ Stage } \\
\hline PUNLMP & 1 & 0 & 1 & 0 & & \\
\hline pTa & 12 & 2 & 7 & 3 & & \\
\hline pT1 & 8 & 3 & 2 & 3 & & \\
\hline pT2 & 1 & 0 & 1 & 0 & 0.615 & NS \\
\hline
\end{tabular}

Grade

(WHO 1999)

$\begin{array}{ccc}1 & 1 & 0 \\ 1-2 & 1 & 0 \\ 2 & 7 & 2 \\ 2-3 & 5 & 2 \\ 3 & 7 & 1\end{array}$

FISH pattern

Low-risk

High-risk

$11 \quad 3$

112

$1 \quad 0$

10

32

21

$3 \quad 3$

NS

DNA ploidy

Diploid

Non-diploid

$12 \quad 3$

102

7

4

$3 \quad 0.870$

p53 expression

$\begin{array}{lll}\leq 10 \% & 8 & 3\end{array}$

$>10 \%$

14

3

2

4

$7 \quad 5$

0.330

NS

MIB1 LI

$\leq 10 \%$

94

$>10 \%$

13

4
1

5

0

$6-6$

7.410

0.025

Molecular grade

\begin{tabular}{lrrrrrr} 
Low & 4 & 3 & 1 & 0 & & 2.830 \\
High & 18 & 2 & 10 & 6 & 0.020 \\
\hline
\end{tabular}

NS, not significant.

ploidy and MIB1 LI (rs 0.308, $\mathrm{P}=0.047$; rs 0.551, $\mathrm{P}<0.000$; rs $0.692, \mathrm{P}<0.000$ and rs $0.405, \mathrm{P}<0.006$, respectively).

Association of tumour morphological and molecular characteristics with clinical outcome. During clinical follow-up (mean 34.41 months and range 3-152), five patients had an uneventful outcome, 11 developed recurrences in the same stage and grade as the primary tumour and 6 showed disease progression with reappearance in advanced stage or grade. The relationship of tumour characteristics and clinical outcome is shown in Table III. A statistically significant association of outcome was found with MIB1 LI $(\mathrm{P}=0.025)$ and molecular grade $(\mathrm{P}=0.02)$.
Progressive tumours were characterized by an increased MIB1 LI and high molecular grade. Recurrence rates were also significantly different between groups with low and high molecular grade tumours as well as with low and high MIB1 LIs ( $\mathrm{P}=0.007$ and $\mathrm{P}=0.008$; Mann-Whitney, respectively).

Patient and tumour characteristics in cases with ambiguous histopathological tumour grade. Distribution of the clinicopathological, molecular and outcome variables in cases with ambiguous histopathological tumour grades is shown in Table IV. Six of 12 patients had clinical follow-up results. Two patients were uneventful at three months, three developed 
Table IV. Patient, tumour and clinical characteristics of 12 urothelial carcinomas with ambiguous histopathological grade according to the WHO 1999 classification.

\begin{tabular}{|c|c|c|c|c|c|c|c|c|c|c|}
\hline $\begin{array}{l}\text { Case } \\
\text { no. }\end{array}$ & $\begin{array}{c}\text { Grade } \\
\text { (WHO 1999) }\end{array}$ & Gender & Age & Outcome & $\begin{array}{l}\mathrm{pT} \\
\text { stage }\end{array}$ & $\begin{array}{c}\text { FISH } \\
\text { pattern }\end{array}$ & $\begin{array}{l}\text { DNA } \\
\text { ploidy }\end{array}$ & $\begin{array}{l}\text { p53 LI } \\
(\%)\end{array}$ & $\begin{array}{l}\text { MIB LI } \\
(\%)\end{array}$ & $\begin{array}{l}\text { Molecular } \\
\text { grade }\end{array}$ \\
\hline 1 & $2-3$ & Male & 52 & $\begin{array}{l}\text { Uneventful } \\
\text { (at } 3 \text { months) }\end{array}$ & pT1 & Low-risk & Diploid & 5 & 6 & Low \\
\hline 2 & $2-3$ & Male & 66 & $\begin{array}{l}\text { Uneventful } \\
\text { (at } 3 \text { months) }\end{array}$ & pT1 & High-risk & Tetraploid & 37 & 5 & High \\
\hline 3 & $2-3$ & Male & 71 & Progression & pT1 & Low-risk & Tetraploid & 37 & 86 & High \\
\hline 4 & $1-2$ & Male & 45 & Recurrence & $\mathrm{pTa}$ & Low-risk & Diploid & 6 & 12 & High \\
\hline 5 & $2-3$ & Male & 74 & Recurrence & pTa & Low-risk & Diploid & 15 & 18 & High \\
\hline 6 & $2-3$ & Male & 72 & Recurrence & pT1 & High-risk & Aneuploid & 74 & 16 & High \\
\hline 7 & $2-3$ & Male & 70 & - & pT1 & High-risk & Aneuploid & 21 & 34 & High \\
\hline 8 & $2-3$ & Male & 63 & - & $\mathrm{pTa}$ & High-risk & Diploid & 15 & 42 & High \\
\hline 9 & $2-3$ & Male & 64 & - & $\mathrm{pTa}$ & Low-risk & Diploid & 6 & 32 & High \\
\hline 10 & $1-2$ & Female & 53 & - & pT1 & Low-risk & Diploid & 84 & 69 & High \\
\hline 11 & $2-3$ & Male & 56 & - & $\mathrm{pTa}$ & Low-risk & Diploid & 41 & 30 & High \\
\hline 12 & $2-3$ & Female & 76 & - & pT1 & High-risk & Aneuploid & 86 & 34 & High \\
\hline
\end{tabular}

recurrences and one experienced tumour progression. Low molecular grade was given only to one pT1 carcinoma which had an uneventful clinical outcome. The other cases were classified as tumours with high molecular grade implicating increased risk for recurrence and progression. Although one of these cases showed an uneventful outcome, this result was yielded as early as 3 months after the operation and no further follow-up data were available. This case together with the other six diagnostic cases, all assigned high molecular grade, should be considered as anticipatory high-risk cases for tumour recurrence and progression.

\section{Discussion}

Only a few studies have analysed the performance and prognostic value of multiple molecular markers in bladder urothelial neoplasias since the introduction of the WHO/ISUP grading scheme (now recognized as the 2004 WHO classification) $(15,20)$. Recent studies have focused mainly on p53 and $\mathrm{Ki}-67 / \mathrm{MIB} 1$ expression indicating that i) the prevalence of p53 alterations increases with stage and grade (21) without being independent prognostic factors, (8) and ii) MIB1 labelling index is significantly associated with recurrence and stage progression and is an independent predictor of diseasefree and overall survival, at least in $\mathrm{pTa} / \mathrm{pT} 1$ bladder UCs $(8,10)$.

This study shows that quantitative assessment of molecular biomarkers can be used to predict the clinical outcome of UCs more accurately than traditional clinicopathological parameters. In particular, the use of a 2-tired molecular classification proved to be superior to the classic 3- or 5-tired histological grading systems and it would be beneficial to render tumours with ambiguous pathological grade to either of the molecular grades. Though the histopathological grade was significantly related to tumour stage (rs $0.31, \mathrm{P}=0.047$ ), it was not associated with clinical outcome and no significant correlation between histological and molecular grade was found. In contrast, molecular grade showed a significant correlation with outcome (rs $0.53, \mathrm{P}=0.012$ ) and tumours with stage or grade progression had high molecular grades.

Regarding single parameters, the p53 labelling index showed no diagnostic and prognostic utility in our present panel of bladder carcinomas. P53 nuclear overexpression was observed in $29(64.4 \%)$ or $22(48.8 \%)$ of our 45 cases depending on the cut-off levels used for a positivity of 10 or $20 \%$, respectively. This is in agreement with published results, which encompass a range between 22-64\% (21). However, we found no significant association of p53 LI in either stage and grade or clinical outcome. The proportion of tumours overexpressing nuclear p53 showed a significantly positive correlation only with the other molecular markers investigated: MIB1 LI, DNA ploidy and FISH pattern (rs 0.40, $\mathrm{P}=0.006$; rs $0.41, \mathrm{P}=0.005$ and rs $0.40, \mathrm{P}=0.007$, respectively), supporting the well-established fact that p53 is a significant member in the molecular progression of bladder UC (8). Our negative results may be due to the relatively small sample size and the limited follow-up, but there may be other important issues as well, regarding counts and rates in immunohistochemistry in general. These include i) the method of counting itself, which is poorly reproducible if performed semiquantitatively (22) and ii) the selection of threshold for positivity, which varies in the literature for UC $(8,10,23)$. In an attempt to overcome these strictly methodical problems, we determined the immunohistochemical scores for p53 and MIB1 staining by using automated cellular image analysis with a large body of wellvalidated evidence for objectivity and reproducibility $(22,24)$ and performed statistical calculations with the two most frequently used cut-offs for a positivity of 10 and $20 \%$, respectively.

The strong prognostic and predictive value of cell proliferative activity as assessed by $\mathrm{Ki}-67 / \mathrm{MIB} 1 \mathrm{LI}$ for the recurrence and progression of UCs has been confirmed by many 
investigators $(10,20,23,24)$. However, sampling and thresholds vary, making the comparison of results difficult. Our results are in line with previous findings of others supporting the significance of the Ki-67/MIB1 positive growth fraction as a determinant of the biological aggressiveness of UC and as a prognostic factor. Ki-67/MIB1 LI measured by automated cellular image analysis at a threshold of $10 \%$ for positivity was the only biomarker in our study which showed significant correlations with the clinicopathological tumour characteristics (stage and grade), clinical outcome (recurrence and progression) and the other molecular markers investigated (p53 LI, DNA ploidy and FISH pattern). This indicates that Ki-67/MIB1 LI may be used to stratify patients with bladder UCs into risk groups assisting therapy decisions in everyday clinical practice. This further underlines the importance of an objective and reproducible assessment of Ki-67/MIB1 LI, which can be achieved by using quantitative image morphometry (22).

Deranged proliferation is a hallmark of malignancy. Cell division errors frequently lead to infidelity of mitotic chromosome segregation and result in numerical and structural chromosomal abnormalities that is probably the major cause of aneuploidy in tumour cells (25). We previously hypothesized that high-frequency polysomies of chromosomes 3, 7 and 17, in addition to 9p21 deletion detected by the UroVysion FISHassay in urine specimens from subjects with bladder UC, may be either a reflection of aneuploidy or genomic instability. This approach proved to be very effective for predicting tumour recurrence and progression of $\mathrm{pTa} / \mathrm{pT} 1 \mathrm{UCs}$ and may be a useful marker for non-invasive surveillance of patients with a history of bladder cancer (16). Our current results indicate that FISH pattern, determined in extracted nuclei of paraffinembedded bladder UCs, is correlated with DNA ploidy (rs $0.82, \mathrm{P}<0.000$ ) and the two markers showed a highly significant correlation with tumour stage (rs 0.55 and 0.70 , respectively). This is supported by the results of others (10$12,26)$. Though FISH pattern and DNA ploidy as single markers were not directly associated with disease outcome in the present cohort, which is probably sampling and follow-up related, but as variables of the multiparametric molecular grade, they contributed to its prognostic value.

The cumulative results of our present pilot study provide further evidence that early genetic changes during urothelial carcinogenesis and progression do not necessarily correlate with observable changes in morphology. Thus, testing for molecular alterations and ploidy in early lesions may identify patients who are at the greatest risk for recurrence and progression and lead to more definitive therapy.

We conclude that the combination of quantitative biomarkers provides significantly better, objective and reproducible prognostic tools in bladder UCs than classic clinicopathological features and indices. Although the prognostic value of the combination of complementary markers is superior to that of single parameters, the majority of information appears to reside in Ki-67/MIB1 LI. The wellestablished robustness and reproducibility of quantitative pathology assessments provide a solid basis for the implementation and routine use of modern pathology methods for individualized prognostication and risk-adapted treatment of patients with bladder UCs.

\section{Acknowledgements}

We would like to thank Dr Harald Griefingholt for data management, Mr. Oliver Hahn and Mr. Oliver Bollmann for digital image analysis and processing.

\section{References}

1. Knowles MA: Molecular subtypes of bladder cancer: Jekyll and Hyde or chalk and cheese? Carcinogenesis 27: 361-373, 2006.

2. Kurth KH, Denis L, Bouffioux C, et al: Factors affecting recurrence and progression in superficial bladder tumors. Eur $\mathrm{J}$ Cancer 31A: 1840-1846, 1995.

3. Millan-Rodriguez F, Chechile-Toniolo G, Salvador-Bayarri J, et al: Multivariate analysis of the prognostic factors of primary superficial bladder cancer. J Urol 163: 73-78, 2000.

4. Tosoni I, Wagner U, Sauter G, et al: Clinical significance of interobserver differences in the staging and grading of superficial bladder cancer. Br J Urol Int 85: 48-53, 2000.

5. Sylvester RJ, van der Meijden AP, Oosterlinck W, et al: Predicting recurrence and progression in individual patients with stage Ta T1 bladder cancer using EORTC risk tables: a combined analysis of 2596 patients from seven EORTC trials. Eur Urol 49: 466-475, 2006.

6. Cordon-Cardo C, Cote RJ and Sauter G: Genetic and molecular markers of urothelial premalignancy and malignancy. Scand J Urol Nephrol 205: 82-93, 2000.

7. Schultz IJ, Witjes AJ, Swinkels DW and de Kok JB: Bladder cancer diagnosis and recurrence prognosis: comparison of markers with emphasis on surviving. Clinica Chimica Acta 368: 20-32, 2006.

8. Lopez-Knowles E, Hernandez S, Kogevinas M, et al: The p53 pathway and outcome among patients with T1G3 bladder tumors. Clin Cancer Res 12: 6029-6036, 2006.

9. Quintero A, Alvarez-Kindelan J, Luque RJ, et al: Ki-67 labelling index and the prognosis of primary TaT1 urothelial cell carcinoma of the bladder. J Clin Pathol 59: 83-88, 2006.

10. Pich A, Chiusa L, Formiconi A, et al: Proliferative activity is the most significant predictor of recurrence in noninvasive papillary urothelial neoplasms of low malignant potential and grade 1 papillary carcinomas of the bladder. Cancer 95: 784-790, 2002 .

11. Holmang S, Andius P, Hedelin H, et al: Stage progression in Ta papillary urothelial tumors: relationship to grade, immunohistochemical statement of tumor markers, mitotic frequency and DNA ploidy. J Urol 165: 1124-1128, 2001.

12. Masters JR, Camplejohn RS, Parkinson MC, et al: DNA ploidy and the prognosis of stage pT1 bladder cancer. Br J Urol 64: 403-408, 1989.

13. Korkolopoulou P, Christodoulou P, Konstantinidou AE, et al: Cell cycle regulators in bladder cancer: A multivariate survival study with emphasis on p27Kip1. Hum Pathol 31: 751-760, 2000.

14. Shariat SF, Zlotta SR, Ashfaq R, Sagalowsky AI and Lotan Y: Cooperative effect of cell cycle regulators expression in bladder cancer development and biologic aggressiveness. Mod Pathol 20: 445-459, 2007.

15. van Rhijn BW, Vis AN, van der Kwast TH, et al: Molecular grading of urothelial cell carcinoma with fibroblast growth factor receptor 3 and MIB-1 is superior to pathologic grade for the prediction of clinical outcome. J Clin Oncol 21: 1912-1921, 2003.

16. Bollmann M, Heller H, Bánkfalvi A, Griefingolt $\mathrm{H}$ and Bollmann R: Quantitative molecular urinary cytology by UroVysion FISH: a tool for tailoring surveillance of patients with superficial bladder cancer? Br J Urol Int 95: 1219-1225, 2005 .

17. Sobin LH and Wittekind Ch (eds): TNM Classification of Malignant Tumors, 6th edition. Wiley-Liss, Inc., Chichester, 2002 .

18. Mostofi FK, Davis CJ and Sesterhenn IA: Histological typing of urinary bladder tumors. In: World Health Organisation. 2nd edition, Springer Verlag, Berlin, 1999.

19. Sauter G, Algaba F, Amin F, et al: Non-invasive urothelial neoplasias. WHO-classification of non-invasive papillary urothelial tumors. In: World Health Organization Classification of Tumors. Pathology and Genetics: Tumors of the Urinary System and Male Genital Organs. Eble JN, Sauter G, Epstein JI and Sesterhenn I (eds). IARCC Press, Lyon, pp89-157, 2004. 
20. Cina SJ, Lancaster-Weiss KJ, Lecksell $\mathrm{K}$ and Epstein JI: Correlation of Ki-67 and p53 with the new World Health Organization/International Society of Urological Pathology classification system for urothelial neoplasias. Arch Pathol Lab Med 125: 646-651, 2001.

21. Vardar E, Gunlusoy B, Minareci S, Postaci H and Ayder AR: Evaluation of p53 nuclear accumulation in low- and high-grade (WHO/ISUP Classification) transitional papillary carcinomas of the bladder for tumor recurrence and progression. Urol Int 77: 27-33, 2006

22. Loukas CG, Wilson GD, Vojnovic B and Linney A: An image analysis-based approach for automated counting of cancer cell nuclei in tissue sections. Cytometry A 55: 30-42, 2003.

23. Yin $\mathrm{H}$ and Leong AS: Histologic grading of noninvasive papillary urothelial tumors. Validation of the 1998 WHO/ISUP system by immunophenotyping and follow-up. Am J Clin Pathol 121: 679-687, 2004.
24. Sun W, Zhang P and Herrera G: p53 protein and Ki-67 overexpression in urothelial dysplasia of bladder. Appl Immunohistochem Mol Morphol 10: 327-331, 2002.

25. Duensing A and Duensing S: Guilt by association? P53 and the development of aneuploidy in cancer. Biochem Biophys Res Com 331: 694-700, 2005.

26. Bol MGW, Baak JPA, van Diermen B, et al: Proliferation markers and DNA content analysis in urinary bladder TaT1 urothelial carcinomas: identification of subgroups with low and high stage progression risks. J Clin Pathol 56: 447-452, 2003. 